12,18

\title{
Структура и электрофизические свойства многостенных углеродных нанотрубок, подвергнутых облучению ионами аргона
}

\author{
(C) Е.В. Князев ${ }^{1}$, В.В. Болотов ${ }^{1,2}$, К.Е. Ивлев ${ }^{1}$, С.Н. Поворознюк ${ }^{1,3}$, В.Е. Кан ${ }^{1}$, Д.В. Соколов ${ }^{1}$ \\ ${ }^{1}$ Омский научный центр СО РАН, \\ Омск, Россия \\ ${ }^{2}$ Омский государственный университет им. Ф.М. Достоевского, \\ Омск, Россия \\ ${ }^{3}$ Омский государственный технический университет, \\ Омск, Россия \\ E-mail: knyazev@obisp.oscsbras.ru \\ (Поступила в Редакцию 25 сентября 2018 г.)
}

Методами комбинационного рассеяния света, растровой и просвечивающей электронной микроскопии, электрофизическими методами исследуется влияние радиационных дефектов на морфологию, структуру и электрофизические характеристики многостенных углеродных нанотрубок (МУНТ). После облучения ионами аргона наблюдается деградация структуры нанотрубок. Отжиг в инертной среде приводит к частичному восстановлению структуры нанотрубок. При этом в их стенках наблюдается локализация участков с восстановленной графеновой структурой и участков, насыщенных протяженными дефектами, искривляющих графеновые слои стенок МУНТ. Такое изменение структуры приводит к резкому снижению проводимости многостенных углеродных нанотрубок.

Работа выполнена с использованием оборудования Омского центра коллективного пользования (ОмЦКП СО РАН)по государственному заданию ОНЦ СО РАН в соответствии с Программой фундаментальных научных исследований государственных академий наук на 2013-2020 годы по направлению II.9, проект № II.9.2.1 (номер госрегистрации в системе ЕГИСУ НИОКТР АААА-А17-117041210227-8) при частичной поддержке гранта РФФИ № 16-08-00763 А и при финансовой поддержке РФФИ и Субъекта РФ Омской области в рамках научного проекта № 18-48-550009 p_a.

DOI: $10.21883 /$ FTT.2019.03.47252.259

\section{1. Введение}

Многостенные углеродные нанотрубки (МУНТ) являются материалом, который пользуется повышенным интересом исследователей и имеет широкое практическое применение в микро- и нано- электронных устройствах $[1,2]$. Высокая механическая прочность, широкий диапазон получаемой проводимости, химическая инертность, развитая поверхность ансамблей многостенных углеродных нанотрубок делают их пригодными для изготовления анодов литий-ионных батарей, электродов суперконденсаторов, газочувствительных слоев газовых сенсоров и т.д. $[3,4]$.

Применение МУНТ в различных областях техники подразумевает возможность управления свойствами нанотрубок и получения материала с требуемыми параметрами. Так материал для электродов суперконденсаторов должен обладать низкими значениями сопротивления и высокой химической инертностью [5]. В свою очередь, когда необходимо использование МУНТ в качестве армирующей структуры для чувствительных слоев газовых наносенсоров, от материала - носителя требуется более высокое сопротивление [2] и химическая активность. Однако до настоящего времени синтез нанотрубок с определенными свойствами остается сложной задачей. Наиболее распространенными методами получения уг- леродных нанотрубок являются дуговой разряд, лазерная абляция и химическое осаждение (Chemical vapor deposition, CVD). Основную долю трубок, полученных методом химического осаждения, составляют МУНТ. Последние обладают высокой проводимостью, низкой сорбционной способностью и низкой химической активностью, что ограничивает их применение, например, в качестве газочувствительных слоев сенсорных наноструктур $[2,6]$.

Структурные особенности углеродных нанотрубок определяют их свойства. В ряде теоретических и экспериментальных работ показано влияние дефектов структуры трубок на их электрофизические свойства [7-9]. Можно предполагать, что управление дефектным составом МУНТ позволит получать нанотрубки с необходимыми для конкретных целей электрофизическими свойствами. Достаточно эффективным способом введения дефектов в структуру МУНТ является облучение потоком заряженных частиц [10]. При этом основными видами вводимых дефектов являются вакансионные дефекты и междоузельные атомы углерода. Известно, что введение вакансии в графеновый слой вызывает перестройку его структуры в области дефекта, а междоузельные атомы углерода оказываются вне графеновой плоскости и, в случае МУНТ, могут образовывать химическую связь между стенками [11]. Помимо фор- 
мирования вакансий и междоузлий, облучение пучками высокоэнергетичных частиц может стимулировать переход углерода от $s p^{2}$-гибридизированного состояния к $s p^{3}$-гибридизации $[12,13]$. В свою очередь, термический отжиг в инертной среде приводит к миграции вакансионных дефектов в стенках МУНТ, что может привести как к восстановлению структуры графеновых стенок, так и к образованию в них мультивакансионных дефектов [14-15].

Таким образом, комбинация ионного облучения и термических обработок является эффективным методом воздействия на морфологию и свойства МУНТ, и может использоваться для направленного изменения электрофизических свойств углеродных нанотрубок. Целью настоящей работы было исследование структуры МУНТ при радиационных и термических обработках и её связи с электрофизическими свойствами индивидуальных нанотрубок и их ансамблей.

\section{2. Эксперимент}

В данной работе исследовались ограниченные массивы МУНТ подверженные воздействию пучка ионов аргона с последующей температурной обработкой в инертной среде с целью проследить изменения морфологии и структуры, а так же оценить влияние данных обработок на электрофизические свойства многостенных углеродных нанотрубок. Слои МУНТ синтезировались методом CVD при пиролизе ацетонитрила, катализатором служили частицы железа, образующиеся в результате разложения ферроцена. Полученные таким образом МУНТ ориентированы нормально к ростовой подложке [6]. После синтеза образцы подвергались отжигу на воздухе при температуре $390^{\circ} \mathrm{C}$ в течение $2 \mathrm{~h}$ для удаления аморфного углерода, формирующегося во время синтеза слоев МУНТ. После термической обработки проводилась химическая очистка образцов в $\mathrm{HCl}(40 \%, 24 \mathrm{~h})$ для удаления частиц катализатора с поверхности МУНТ. Очищенные МУНТ диспергировались в ультразвуковой ванне и полученная суспензия на основе этанола наносились спрей-методом на поверхность монокристаллического кремния. В объеме полученного ансамбля нанотрубки располагаются преимущественно копланарно поверхности, за счет чего повышается эффективность ионного воздействия.

Проводилось облучение ионами аргона энергией $5 \mathrm{keV}$, доза $-1 \cdot 10^{16} \mathrm{~cm}^{-2}$. Термоотжиги проводились в атмосфере аргона при температуре $900^{\circ} \mathrm{C}$ в течение $30 \mathrm{~min}$.

Структура МУНТ исследовалась методами просвечивающей электронной микроскопии (ПЭМ) с использованием электронного микроскопа JEOL JEM-2100, растровой электронной микроскопии (РЭМ) на микроскопе JEOL JSM-6610 LV и спектроскопии комбинационного рассеяния света (КРС) с использованием рамановского фурье-спектрометра BRUKER RFS-100/s.
Тестовые структуры для электрофизических измерений представляли собой систему встречноштыревых золотых контактов (расстояние между проводниками $5 \mu \mathrm{m})$, между которыми спрей-методом помещались разреженные ансамбли МУНТ. Измерения проводились на LCR-метре Agilent E4980. Изменение проводимости МУНТ оценивалось по вольт-амперным характеристикам (BAX) тестовых структур.

\section{3. Результаты}

Исходные МУНТ обладают металлическим характером проводимости, о чем свидетельствует линейный характер ВАХ тестовых структур (рис. 1). Исследования электрофизических свойств МУНТ показывают, что после каждого типа воздействия наблюдается существенное снижение проводимости нанотрубок и их ансамблей (таблица). Так сопротивление ансамбля исходных МУНТ составляет $\sim 0.16-4 \mathrm{~K} \Omega$, что сопоставимо с литературными данными [10].

Облучение углеродных нанотрубок ионами аргона привело к росту сопротивления с $\sim 4 \mathrm{~K} \Omega$ до $55 \mathrm{~K} \Omega$. Такой эффект, вероятно, связан с введением точечных дефектов в структуру нанотрубок, которые являются центрами рассеяния и существенно снижают подвижность носителей заряда. Термическая обработка в инертной атмосфере аргона предварительно облученных нанотрубок также существенно увеличивает сопротивление исследуемого ансамбля МУНТ до $~ 0.4-2.5 \mathrm{MOm}$. Отжиги в инертной атмосфере МУНТ, насыщенных радиационными дефектами, приводят к восстановлению

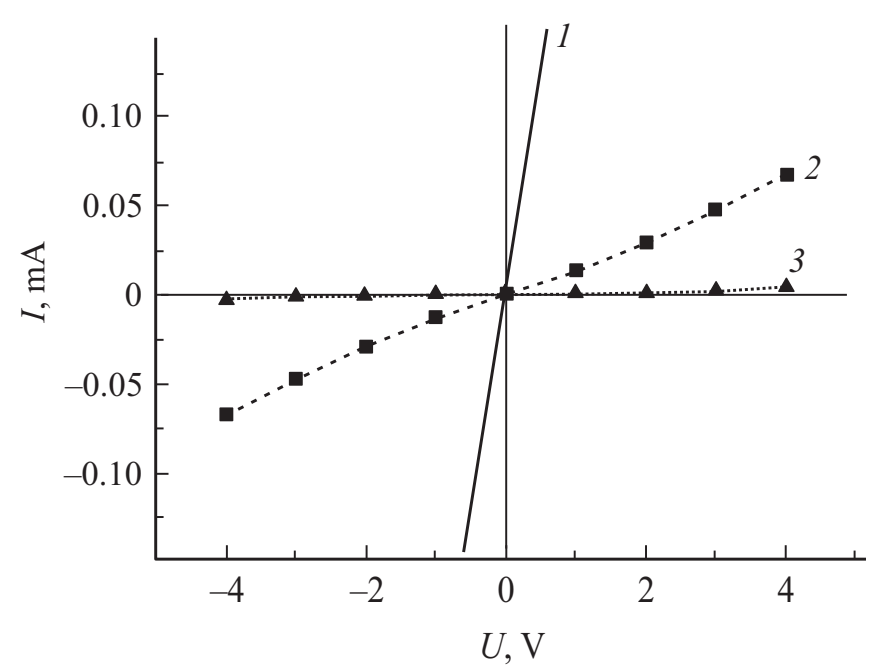

Рис. 1. Вольт-амперные характеристики тестовых структур ограниченных массивов МУНТ. 1 - ограниченный массив МУНТ до ионных и температурных обработок( образец № 3); 2 - массив МУНТ, подверженный облучению ионами $\mathrm{Ar}^{+}$ (образец № 4); 3 - массив МУНТ, подверженный облучению ионами $\mathrm{Ar}^{+}$, с последующей термической обработкой в атмосфере $\operatorname{Ar}$ (образец № 8). 
Сопротивление ограниченного ансамбля МУНТ до и после воздействия

\begin{tabular}{|c|c|c|c|c|c|c|c|c|c|}
\hline \multirow{2}{*}{$\begin{array}{c}\text { Тип воздействия } \\
\text { Образец, № }\end{array}$} & \multicolumn{3}{|c|}{$\begin{array}{c}\text { МУНТ до ионных } \\
\text { и температурных обработок }\end{array}$} & \multicolumn{3}{|c|}{$\begin{array}{l}\text { МУНТ, подверженные } \\
\text { облучению ионами } \mathrm{Ar}^{+}\end{array}$} & \multicolumn{3}{|c|}{$\begin{array}{c}\text { МУНТ, подверженные } \\
\text { облучению ионами } \mathrm{Ar}^{+}, \\
\text {с последующей термической } \\
\text { обработкой в атмосфере } \mathrm{Ar}\end{array}$} \\
\hline & 1 & 2 & 3 & 4 & 5 & 6 & 7 & 8 & 9 \\
\hline $\begin{array}{l}\text { Сопротивление } \\
\text { ансамбля МУНТ }(R, \mathrm{k} \Omega)\end{array}$ & 3.89 & 0.5 & 0.16 & 55 & 5.4 & 11.7 & 400 & 2600 & 960 \\
\hline
\end{tabular}

графеновых слоев за счет рекомбинации точечных дефектов [14], однако экстремальной рост сопротивления указывает на дальнейшую трансформацию структурных дефектов в стенках нанотрубок.

Для оценки влияния ионного воздействия и термических обработок на структуру МУНТ была использована интегральная методика комбинационного рассеяния света.

В спектрах КРС исходных ансамблей МУНТ (рис. 2, кривая 1 ) присутствуют интенсивные $D$ - и $G$-полосы, характерные для графитоподобных материалов $[6,16]$. $G$-полоса в спектре исходного слоя МУНТ имеет мак-

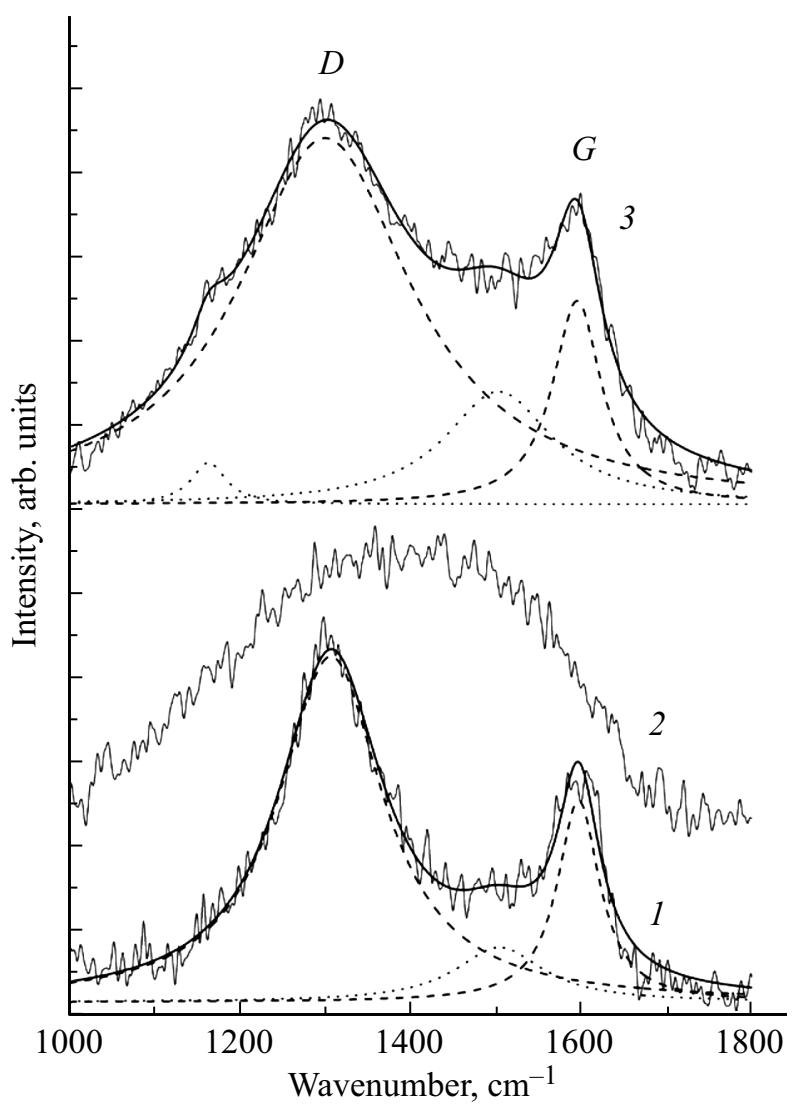

Pис. 2. Спектры КРС ограниченных масивов МУНТ: 1 - массив МУНТ до ионных и температурных обработок; 2 - массив МУНТ, подверженный облучению ионами $\mathrm{Ar}^{+} ; 3$ - массив МУНТ, подверженный облучению ионами $\mathrm{Ar}^{+}$, с последующей термической обработкой в атмосфере Ar. симум при $1583 \mathrm{~cm}^{-1}$, характерный для высокоупорядоченных углеродных материалов с $s p^{2}$-гибридизацией. Анализ спектра исходных МУНТ (см. рис. 1, кривая 1) выявляет полосу при $1500 \mathrm{~cm}^{-1}$, свидетельствующую о наличии аморфного углерода в образце [16]. При воздействии пучка ионов аргона происходит практически полное разупорядочение структуры МУНТ, о чем свидетельствуют исчезновение выделенных $D$ - и $G$-полос в спектрах КРС и появление на их месте широкой полосы, характерной для аморфного углерода (см. рис. 2, кривая 2). В спектрах КРС образцов, подверженных отжигу при $900^{\circ} \mathrm{C}$ после облучения, надежно идентифицируются $D$ - и $G$-полосы, что говорит об изменении структуры дефектных УНТ при термообработке (см. рис. 2, кривая 3). При детальном анализе спектра можно выделить полосу при $1100-1200 \mathrm{~cm}^{-1}$. Ее наличие можно связать с присутствием в слоях фракции $s p^{3}$-гибридизированного углерода [17]. В спектрах слоев МУНТ после облучения и отжига также присутствует широкая полоса при $1500 \mathrm{~cm}^{-1}$. Это свидетельствует о неполном восстановлении графеновой структуры МУНТ с образованием дефектных областей в стенках нанотрубок, атомы углерода в которых являются четырехкоординированными.

По данным РЭМ, исходные ансамбли МУНТ состояли из нанотрубок с диаметрами 20-100 nm (рис. 3, $a$ ), при этом большая часть трубок $(\sim 85 \%)$ имеет внешний диаметр от 20 до $60 \mathrm{~nm}$. На РЭМ-изображениях слоя МУНТ видно, что трубки располагаются преимущественно параллельно подложке, образуя сеть со множеством пересечений трубок, что обусловлено методом нанесения МУНТ на подложку. Толщина слоя нанотрубок варьировалась от 1 до $5 \mu \mathrm{m}$.

В результате воздействия ионов $\mathrm{Ar}^{+}$на ансамбли МУНТ, наблюдается значительное уменьшение числа трубок с диаметром менее $40 \mathrm{~nm}$ (рис. 2,b). Большинство нанотрубок приобрело значительную неравномерность по внешнему диаметру. У отдельных трубок толщина меняется от 80 до $30 \mathrm{~nm}$. В ряде случаев, в местах соприкосновения двух или более трубок наблюдаются спаивание трубок между собой с образованием перепонки между ними, а также образование жгутов МУНТ. Помимо этого появляются многочисленные обрывы трубок, имеющие округлую форму и размер $70 \pm 20 \mathrm{~nm}$. Эти обрывы произошли, вероятно, 


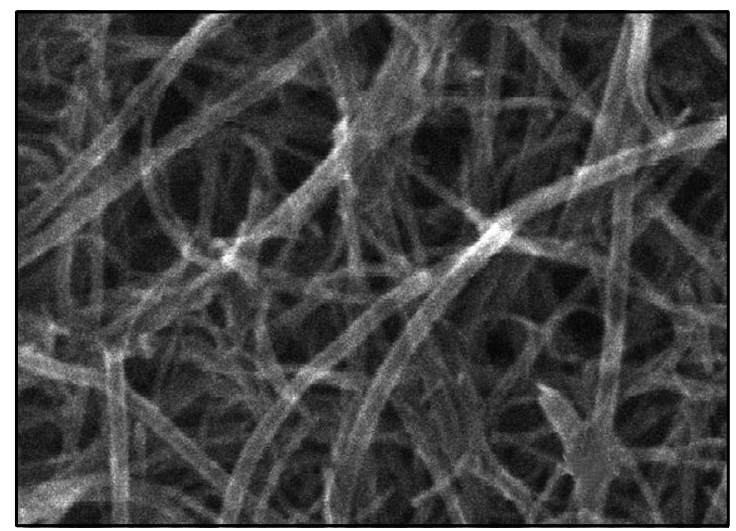

$-200 \mathrm{~nm}$

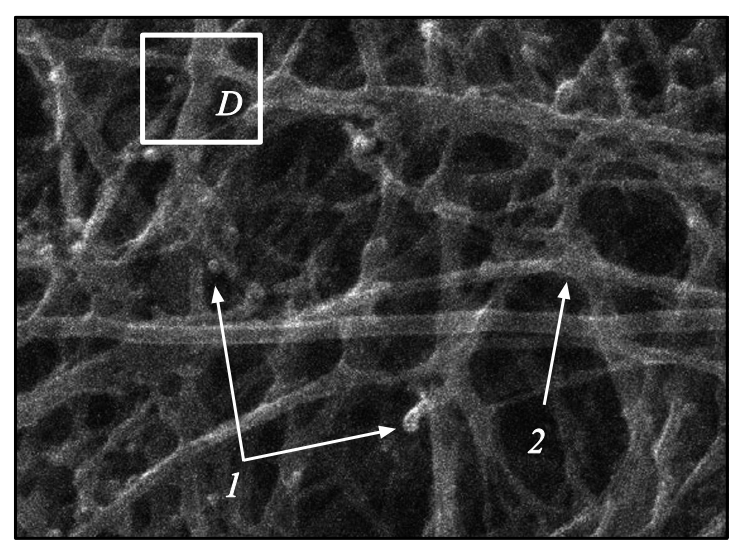

$-200 \mathrm{~nm}$ $a$

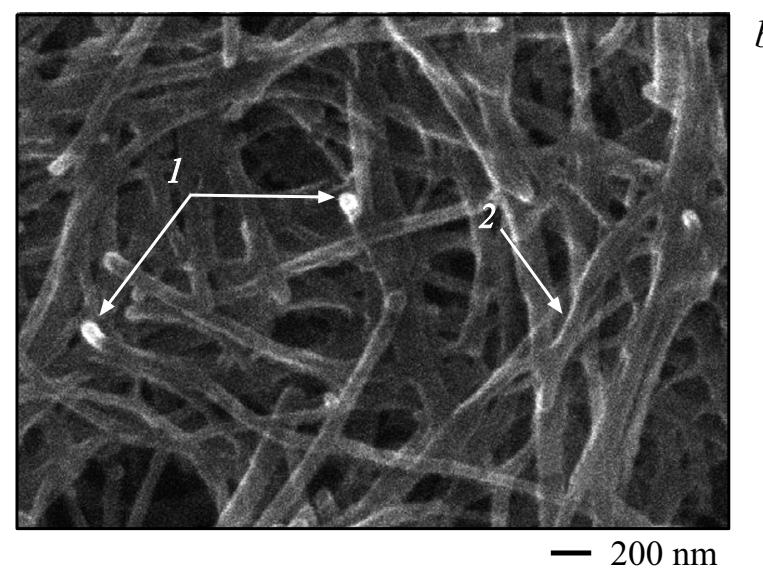

$b$

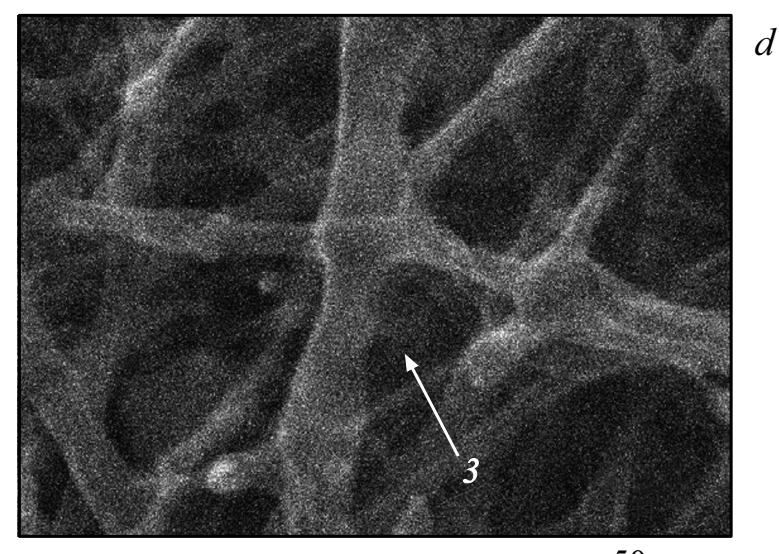

$-50 \mathrm{~nm}$

Рис. 3. РЭМ-изображение ансамбля МУНТ. $a$ - массив МУНТ до ионных и температурных обработок; $b-$ массив МУНТ, подверженный облучению ионами $\mathrm{Ar}^{+} ; c$ - массив МУНТ, подверженный облучению ионами $\mathrm{Ar}^{+}, \mathrm{c}$ последующей термической обработкой в атмосфере $\operatorname{Ar} ; d-$ выделенный фрагмент с рис. 3, $c .1-$ обрывы трубок; $2-$ спайки двух и более углеродных трубок; 3 -- изменение диаметра трубки.

при локальном распылении дефектных участков МУНТ в процессе облучения. (рис. $3, b)$.

Термические обработки приводят к миграции дефектов, поэтому следует ожидать дальнейшей модификации структуры МУНТ после отжигов. Так, на снимках в РЭМ наблюдается частое изменение диаметра нанотрубок, при этом нанотрубка приобретает гофрированный вид (рис. 3,d). Также наблюдаются сшивание трубок, с образованием жгута и спаивание двух и более нанотрубок (рис. 3,c).

Данные просвечивающей электронной микроскопии коррелируют с данными КРС и РЭМ. В ПЭМ-изображениях исходных МУНТ видна бамбукообразная структура МУНТ, характерная для данного вида синтеза [13]. Отчетливо видна структура стенок МУНТ (рис. 4), состоящих из протяженных и относительно ровных отдельных слоев.

Данные ПЭМ свидетельствуют о формировании множества точечных дефектов в структуре нанотрубки после облучения ионами аргона. Графеновые слои стенок МУНТ имеют разрывы и искривления, что, вероятно, связано с перестройкой графеновых плоскостей при фор-

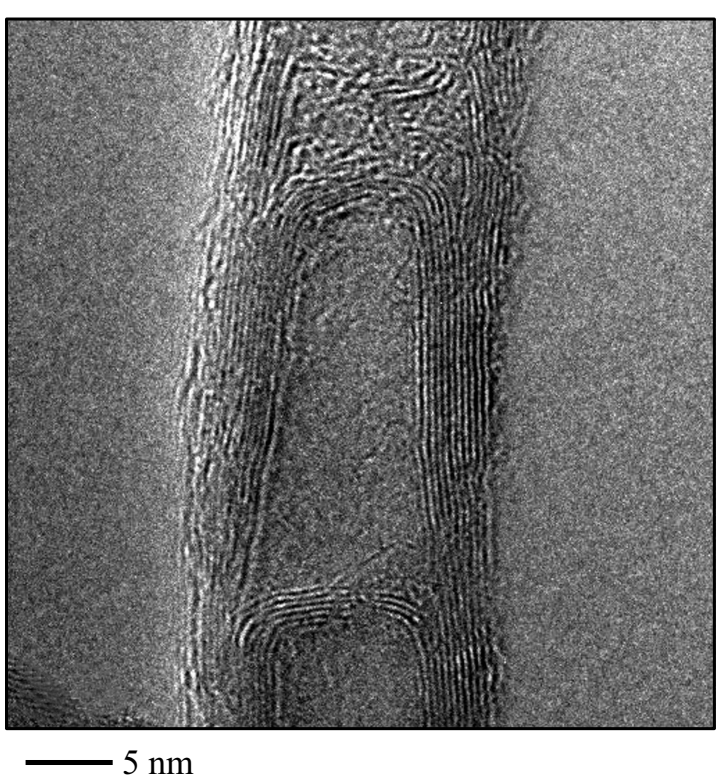

Рис. 4. ПЭМ-изображение МУНТ до ионных и температурных обработок. 

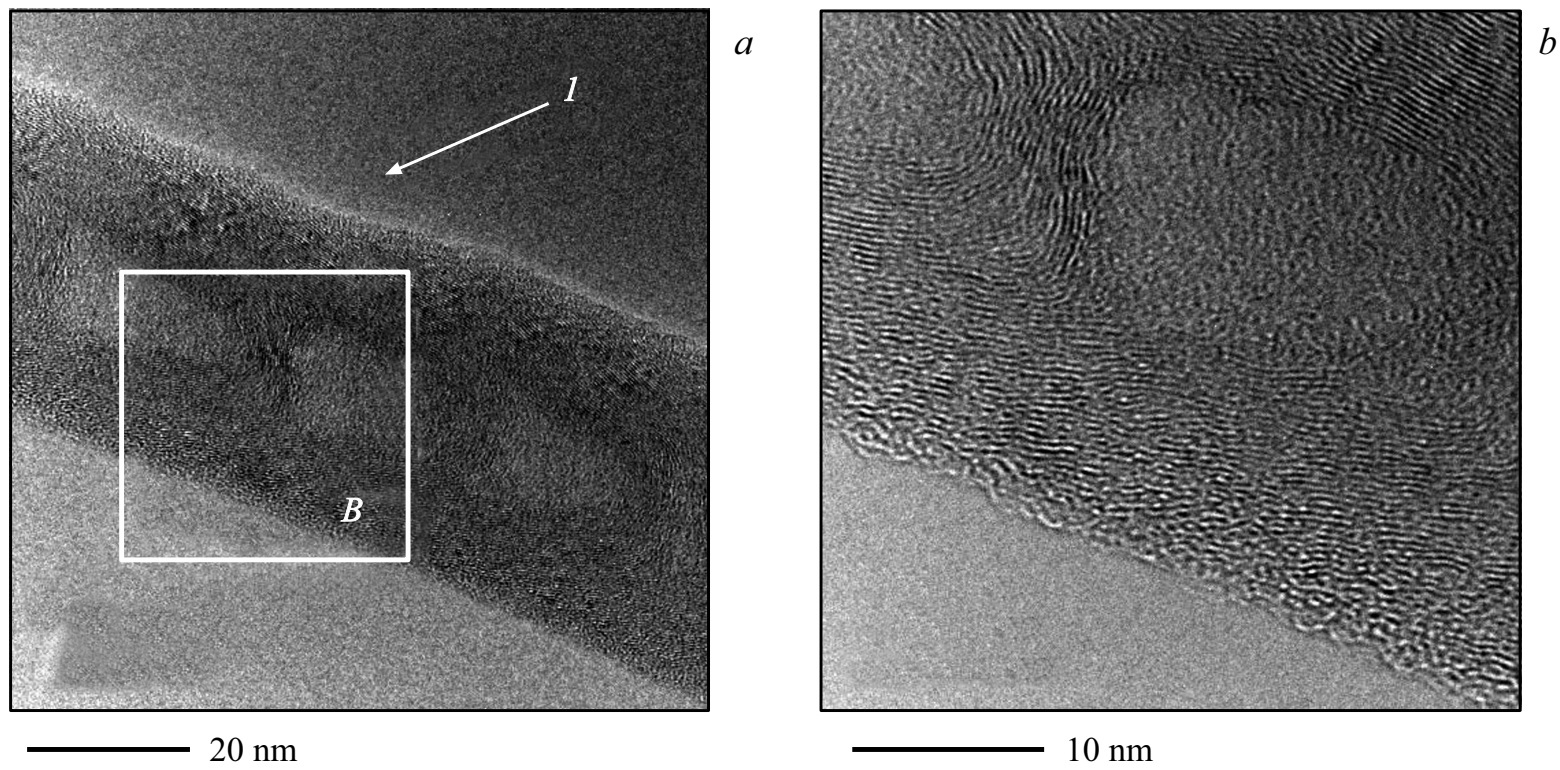

Рис. 5. ПЭМ-изображение МУНТ, подверженные облучению ионами $\mathrm{Ar}^{+}$. $a-$ общий вид нанотрубки; $b-$ структура стенки нанотрубки. 1 - область с удаленными внешними слоями стенки МУНТ.

мировании вакансионных дефектов [14]. По результатам быстрого фурье-преобразования, межслоевое расстояние графеновых слоев после облучения увеличивается с $0.34 \mathrm{~nm}$ до $0.38 \mathrm{~nm}$. Также на внешней поверхности нанотрубки наблюдается удаления части графеновых слоев (рис. 5,a). Однако при данной плотности облучения не наблюдается полной аморфизации стенок нанотрубки (рис. $4, b)$.

Известно, что высокотемпературный отжиг в инертной атмосфере приводит к восстановлению структуры МУНТ $[14,17,18]$. Однако данные ПЭМ свидетельствуют о неполном восстановлении структуры трубок после отжига (рис. 6,a). На некоторых участках трубок наблюдается восстановление графеновых слоев. Структура стенок МУНТ становится схожей с исходными образцами (рис. $6, c)$. Однако также наблюдается формирование протяженных дефектов в стенках трубок, затрагивающих все графеновые слои трубки (рис. $6, b$ ). Такие дефекты приводят к локальному искривлению стенки трубки. При этом наблюдается формирование изгиба графеновых слоев стенки МУНТ. При значительных количествах протяженных дефектов в структуре стенки МУНТ наблюдается чередование участков стенки с изгибом и восстановленной графеновой структурой (рис. 6,a). Схожее поведение графеновых слоев наблюдается при формировании мультивакансионных дефектов [15].

Такое изменение структуры нанотрубок можно объяснить миграцией междоузельных атомов углерода при отжиге. При этом происходит рекомбинация вакансий и междоузельных атомов углерода о чем свидетельствует восстановление графеновой структуры стенок МУНТ. Помимо миграции междоузельных атомов углерода, обладающих высокой подвижностью в стенках МУНТ, возможна и миграция вакансий, на что указывают авторы теоретических исследований $[11,15]$. Вакансионные дефекты способны взаимодействовать с образованием вакансионных кластеров, обладающих меньшей подвижностью.

\section{4. Обсуждение}

Исследование показало связь электрофизических свойств МУНТ с их структурой. Ионные и термические обработки значительно изменяют морфологию отдельных нанотрубок и их ансамблей, при этом наблюдается рост сопротивления образцов с $\sim 4$ до $10^{-55} \mathrm{~K} \Omega$ (таблица).

Как показывают данные спектроскопии КРС и электронной микроскопии, при ионных обработках происходит деградация внутренней структуры МУНТ. При этом нарушается пространственная упорядоченность бензольных колец в графеновых стенках нанотрубок, характерных для $s p^{2}$-гибридизированных атомов углерода (рис. 1, кривая 2). В целом растет дефектность и разупорядоченность стенок МУНТ, происходит аморфизация стенок МУНТ (рис. 5,b), разрушение внешних графеновых слоев (рис. $5, a$ ) и увеличение межслоевого расстояния стенок МУНТ. Благодаря появлению разорванных связей и адатомов, происходит образование жгутов и спаек нанотрубок (рис. $3, b$ ). Таким образом, рост сопротивления ансамбля МУНТ после облучения можно связать с введением радиационных дефектов в графитоподобную структуру стенок МУНТ. Такие дефекты действуют как рассеивающие центры и центры захвата свободных носителей, и, как следствие, снижением подвижности носителей заряда $[9,19]$. 


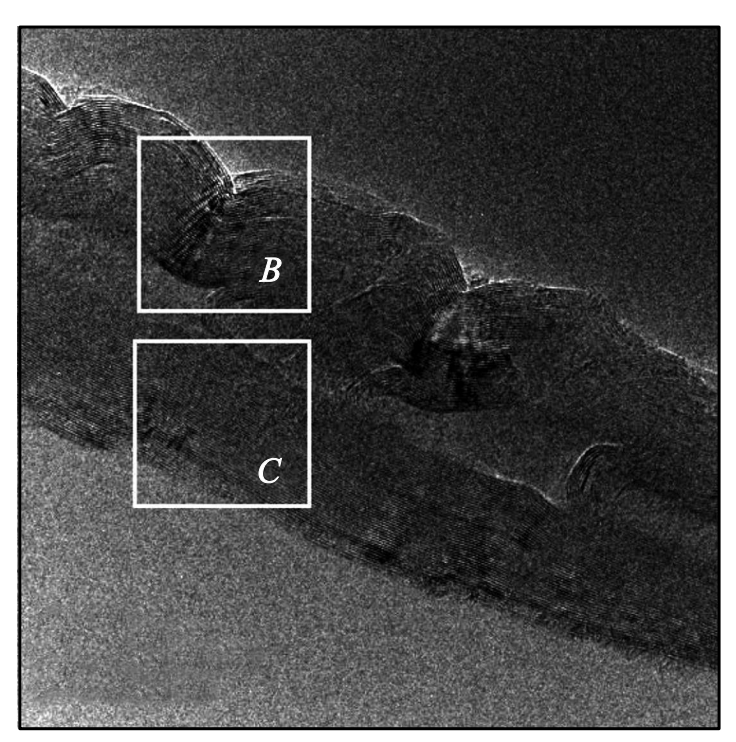

$20 \mathrm{~nm}$

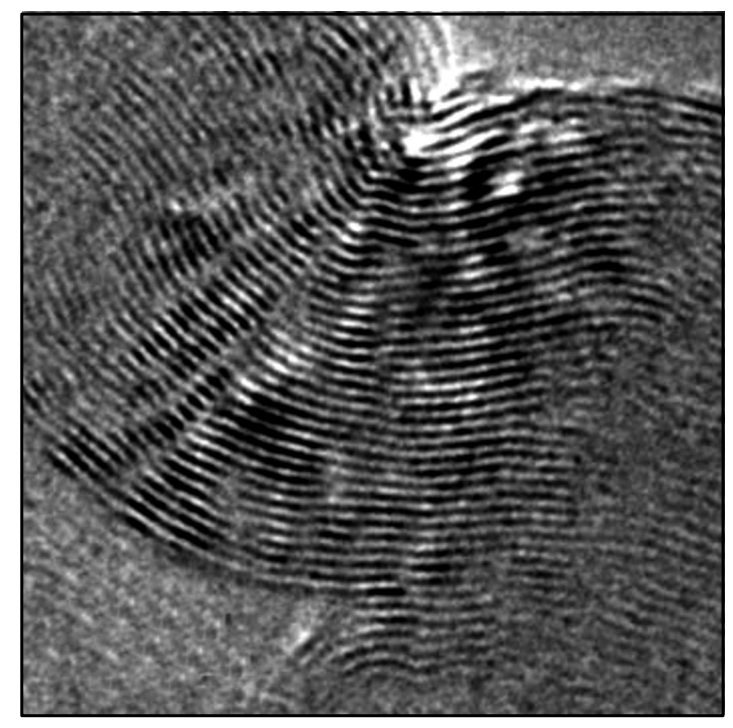

$5 \mathrm{~nm}$

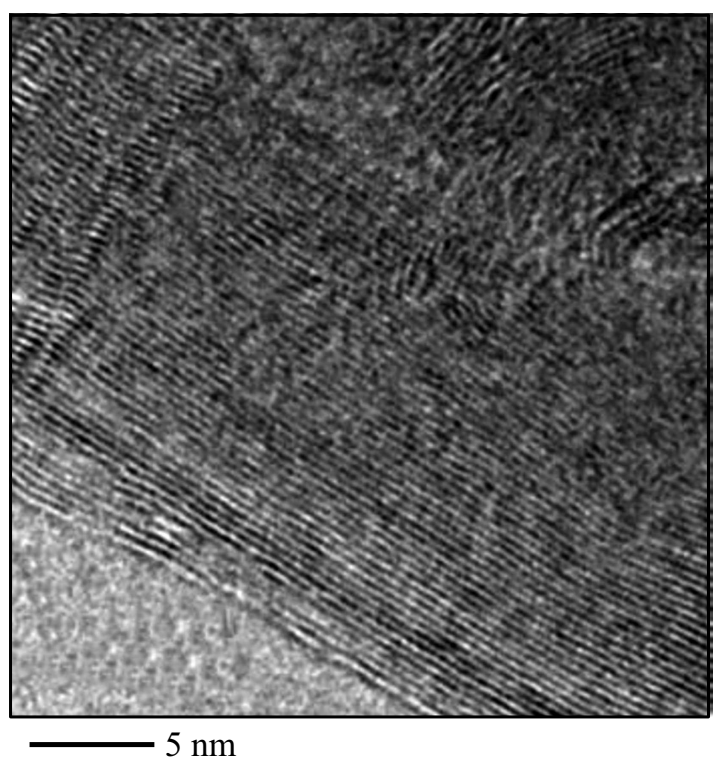

$c$

Рис. 6. ПЭМ-изображение МУНТ, подверженные облучению ионами $\mathrm{Ar}^{+}$, с последующей термической обработкой в атмосфеpe Ar; $a$ - общий вид нанотрубки; $b$ - изображение выделенного дефекта стенки МУНТ; $c$ - восстановленные после отжига графеновые слои стенки МУНТ.

Отжиг в среде аргона при температуре $900^{\circ} \mathrm{C}$ приводит к дальнейшему росту сопротивления исследуемого материала до $\sim 0.4-2.6 \mathrm{M} \Omega$, наряду с частичным восстановлением структуры в МУНТ (рис. 1, кривая 3). Такое поведение можно связать с дальнейшей трансформацией дефектов. Так, данные электронной микроскопии и КРС указывают на наличие процессов рекристаллизации структуры МУНТ при термических обработках, приводящих к частичному восстановлению морфологии трубок.

Стенки МУНТ после отжига состоят из последовательно чередующихся участков с восстановленной графитоподобной структурой и обширных разупорядоченных и дефектных областей (рис. $6, a$ ). На участках с вос- становленной структурой наблюдается восстановление межслоевого расстояния - с $0.38 \mathrm{~nm}$ после облучения до $0.34 \mathrm{~nm}$ после отжига. Участки с восстановленными графеновыми слоями перемежаются с участками с искривлениями и закруглениями стенки МУНТ, содержащими протяженные дефекты (рис. 6, $b$ ) [20]. В дефектных областях, вероятно, существенно снижена подвижность носителей заряда, а чередование с графитоподобными участками создает цепь последовательно соединенных гетеропереходов.

Таким образом, рост сопротивления после отжига может объясняться геометрическим фактором, связанным с уменьшением сечения проводника после обработок, а также последовательным чередованием в стенке МУНТ 
участков с восстановленной графеновой структурой и разупорядоченных областей, на границах которых возможно формирование гетеропереходов и потенциальных барьеров для протекания тока.

\section{5. Заключение}

Данные электрофизических исследований, комбинационного рассеяния света и электронной микроскопии показали возможность направленного изменения внутренней структуры многостенных углеродных нанотрубок путем воздействия на них ионного облучения и последующих отжигов в инертной атмосфере. Комбинация данных воздействий является эффективным способом функционализации углеродных нанотрубок и модификации их электрофизических свойств.

Авторы выражают благодарность Ю.А. Стенькину за синтез МУНТ и М.В. Тренихину за помощь в проведении эксперимента.

\section{Список литературы}

[1] Г.С. Иванченко, Н.Г. Лебедев. ФТТ 51, 2281 (2009).

[2] В.В. Болотов, В.Е. Кан, П.М. Корусенко, С.Н. Несов, С.Н. Поворознюк, И.В. Пономарева, В.Е. Росликов, Ю.А. Стенькин, Р.В. Шелягин, Е.В. Князев. ФТТ 54, 154 (2012).

[3] И.В. Запороцкова, Н.П. Борознина, Ю.Н. Пархоменко, Л.В. Кожитов. Изв. вузов. Материалы электрон. техники 5, 21 (2017).

[4] P. Bondavalli, P. Legagneux, D. Pribat. Sensors Actuators B 140, 304 (2009).

[5] P. Jampani, A. Manivannan, P.N. Kumta. The Electrochem. Soc. Interface 19, 57 (2010).

[6] В.В. Болотов, В.Е. Кан, Н.А. Давлеткильдеев, И.В. Пономарева, О.В. Кривозубов, А.В. Окотруб, А.Г. Кудашов. Перспектив. материалы 3, 24 (2009).

[7] R. Juarez-Mosqueda, M. Ghorbani-Asl, A. Kuc, T. Heine. Phys. Chem. C 118, 13936 (2014).

[8] S. Baldo, S. Scuderi, V. Tripodi, L. La Magna, A. Leonardi, S.G. Donato, N. Neri, G. Filice, S. Scalese, S.J. Sens. Sens, Syst. 4, 25 (2015).

[9] Y. Ma, B. Yin, H. Bai, X. Ding, Y. Cao, Q. Li, Y. Ji. Mater. Res. Express 3, 055016 (2016)

[10] A. Ishaq, L. Yan, D. Zhu. Instrum. Meth. Phys. Res. B 267, 1779 (2009).

[11] O. Lehtinen, T. Nikitin, A.V. Krasheninnikov, L. Sun, F. Banhart, L. Khriachtchev, J. Keinonen. New J. Phys. 13, 073004 (2011).

[12] A. Ishaq, Shahid Iqba, Naveed Ali, A.A. Khurram, A.U. Akrajas, C.F. Dee, Shahzad Naseem, H.M. Rafique, Yan Long. New Carbon Mater. 28, 81 (2013).

[13] V.V. Bolotov, P.M. Korusenko, S.N. Nesov, S.N. Povoroznyuk, E.V. Knyazev. Nucl. Instrum. Meth. Phys. Res. 337, 1 (2014).

[14] Z. Xu, L. Xu, F. Fang, H. Gao, W. Li. Nucl. Instrum. Meth. Phys. Res. B 307, 203 (2013).
[15] J.Y. Huang, S. Chen, Z.F. Ren, Z.Q. Wang, D.Z. Wang, M. Vaziri, Z. Suo, G. Chen, M.S. Dresselhaus. Phys. Rev. Lett. 97, 075501 (2006).

[16] В.В. Болотов, В.Е. Кан, М.Ю. Бирюков, Е.В. Князев, Р.В. Шелягин, Ю.А. Стенькин. ФТТ 55, 1360 (2013).

[17] A.C. Ferrari, J. Robertson. Phys. Rev. B 63, 121405 (2001).

[18] A. Figaro, J. Pourchez, D. Boudard, V. Forest, S. Berhanu, J.M. Tulliani, J.-P. Lecompte, M. Cottier, D. Bernache-Assollant, P. Grosseau. J. Nanopart Res. 17, 194 (2015).

[19] Н.А. Давлеткильдеев, Д.В. Соколов, В.В. Болотов, И.А. Лобов. ПЖТФ 43, 47 (2017).

[20] Reetu Kumari, Fouran Singh, Brajesh S. Yadav, Ravinder K. Kotnala, Koteswara Rao Peta, Pawan K. Tyagi, Sanjeev Kumar, Nitin K. Puri. Nucl. Instrum. Meth. Phys. Res. B 412, 115 (2017).

Редактор К.В. Емцев 